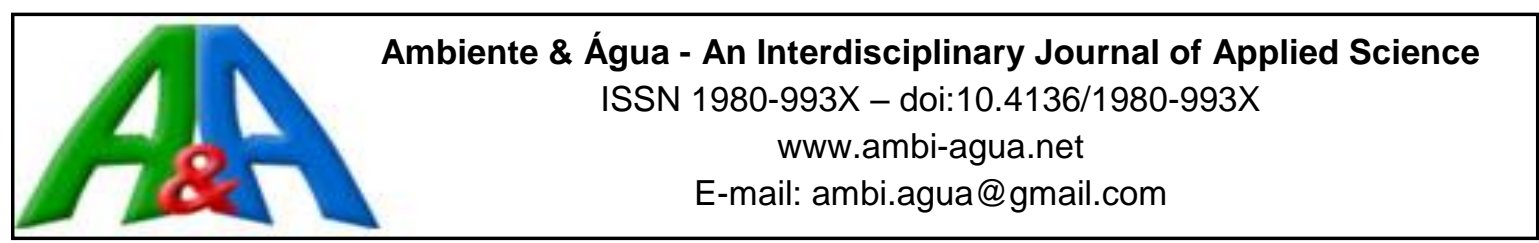

\title{
O mercado brasileiro da energia eólica, impactos sociais e ambientais
}

\author{
doi:10.4136/ambi-agua.2064
}

Received: 24 Jan. 2017; Accepted: 10 Oct. 2017

\section{Lucía Iracema Chipponelli Pinto ${ }^{1 *}$; Fernando Ramos Martins²; Enio Bueno Pereira ${ }^{1}$}

\author{
${ }^{1}$ Instituto Nacional de Pesquisas Espaciais (INPE), São José dos Campos, SP, Brasil \\ Centro de Ciência do Sistema Terrestre (CCST). E-mail: lucia.chipponelli@inpe.br, enio.pereira@inpe.br \\ ${ }^{2}$ Universidade Federal de São Paulo (UNIFESP), Santos, SP, Brasil \\ Campus Baixada Santista, Instituto do Mar. E-mail: fernando.martins@unifesp.br \\ *Autor correspondente
}

\section{RESUMO}

Atualmente a energia eólica está mostrando destaque no cenário energético brasileiro por ser uma fonte energética renovável que apresenta elevada disponibilidade no território e cujo aproveitamento baixos níveis de emissão de gases de efeito estufa. Em razão desses aspectos, a energia eólica é uma promissora alternativa para ajudar a reverter o quadro atual de crise energética decorrente da escassez do recurso hídrico e o crescimento da emissão de gases de efeito estufa decorrente do crescimento da participação de combustíveis fósseis na matriz elétrica brasileira. Na perspectiva econômica, a geração eólica está apresentando custos competitivos com as fontes convencionais de energia. Entretanto, como qualquer outra atividade econômica, pode causar impactos sociais e ambientais que devem ser analisados e mitigados. Essas dimensões controversas da energia eólica tornam a questão da localização de parques eólicos um problema bastante complexo, dado a incompatibilidade entre esses impactos de caráter localizado e o grande benefício público associado à segurança energética do país. Este artigo apresenta uma revisão dos estudos e publicações sobre o aproveitamento eólico no Brasil com o intuito de promover uma discussão sobre aspectos relacionados aos impactos socioambientais. Em razão da curta história do aproveitamento eólico no Brasil, estudos para avaliação mais aprofundada dos impactos socioambientais devem ser realizados com apoio de recursos do próprio setor energético a fim de promover um crescimento sustentável da participação desta fonte energética na matriz elétrica nacional.

Palavras-chave: energia eólica, segurança energética, impactos ambientais e sociais.

\section{Social and environmental impacts of the Brazilian wind energy market}

\section{ABSTRACT}

The share of wind power is rapidly increasing in the Brazilian energy market due to its large potential in some Brazilian regions and its renewability as a resource, presenting low GHG emissions compared to other energy resources. Wind energy is therefore a promising alternative given the current energy security crisis caused by more frequent water shortages. The wind power generation is presenting competitive costs with conventional energy sources. Wind farms, however, like any other economic activity, may have social and environmental impacts 
that must be investigated and mitigated. These controversial dimensions of wind energy make the location of wind farms a very complex problem, given the conflicting interests between local impacts and the nationwide benefit related to energy security and a cleaner energy matrix. This article presents a review of publications on wind power in Brazil in order to promote a discussion of aspects related to its social and environmental impacts. Due to the short history of wind power plants in Brazil, studies including a more-detailed assessment of socioenvironmental impacts must be conducted with financial support from the energy sector itself to promote sustainable growth of wind power in the Brazilian electricity matrix.

Keywords: wind energy, energy security, environmental and social impacts.

\section{INTRODUÇÃO}

Recentemente, temas relacionados à degradação do meio ambiente e às mudanças climáticas têm feito parte frequente dos noticiários e de discussões entre cientistas, órgãos governamentais e mundo empresarial. Nesse contexto, a questão energética é preocupação urgente, já que os processos convencionais de geração de energia elétrica estão entre os principais responsáveis pelas emissões de Gases de Efeito Estufa (GEE) (Pazheri et al., 2014).

As tendências de crescimento do consumo de combustíveis fósseis são insustentáveis do ponto de vista ambiental e não deveriam ser mantidas a longo prazo com o intuito de reduzir o impacto sobre as mudanças globais. A International Energy Agency (IEA) em sua publicação World Energy Outlook-2013 apresentou um prognóstico de crescimento de 56\% no aproveitamento desse tipo de combustível até 2040 em nível global.

$\mathrm{O}$ Brasil está entre os países que mais emitem $\mathrm{CO}_{2}$ no mundo, durante muitos anos o principal contribuinte para as emissões não foi o setor energético, mas a alta taxa de desmatamento e queimadas na Floresta Amazônica (Loaire et al., 2009). No entanto, a evolução das emissões de GEE, conforme apresentada no Sistema de Estimativa de Emissão de Gases de Efeito Estufa (SEEG), indica que o setor de energia apresentou a maior taxa média de crescimento anual de emissões de GEE no período 2013-2015. As emissões do setor partiram de um patamar de 220,8 milhões de toneladas de dióxido de carbono equivalente $\left(\mathrm{CO}_{2}\right)$ em 1990 para 449,3 milhões de toneladas em 2013, superando as emissões da agropecuária e praticamente equiparando-se às emissões por mudança de uso da terra (Azevedo et al., 2017).

O Brasil vem mantendo um esforço contínuo para manutenção de uma matriz energética limpa no intuito de atender os compromissos internacionais assumidos (Malagueta et al., 2014; Brasil, 2015; Santos et al., 2017). A Oferta Interna de Energia Elétrica (OIEE) no Brasil, para o ano de 2015, ficou em 615,9 TWh. Por fonte, merecem destaque os aumentos de 5,8\% de eletricidade gerada a partir do bagaço de cana e de $7,1 \%$ de energia gerada por lixívia e outras bioenergias. No entanto, a geração eólica apresentou um crescimento vertiginoso no mesmo período, registrando uma oferta de energia $77,1 \%$ superior ao período anterior. Por outro lado, a oferta de eletricidade gerada a partir de óleo de origem fóssil e de gás natural recuaram 19,0\% e 2,0\%, respectivamente para o ano de 2015 (Brasil, 2016). Vale ressaltar que houve um pequeno recuo na oferta interna de energia no período 2014-2015 em razão da crise econômica que o país atravessou e que contribuiu para o recuo significativo no consumo de gás natural.

O Brasil é um país privilegiado sob o aspecto energético, pois seu relevo, hidrografia e clima tropical permitem o aproveitamento das diversas fontes renováveis de energia, como a hidráulica, biomassa, eólica e solar (Amarante et al., 2001; Martins et al., 2008; Costa et al., 2013; Schmidt et al., 2016). A Figura 1 mostra a participação das diversas fontes de energia na matriz elétrica brasileira, sendo que as usinas hidrelétricas contribuem com mais da metade da geração de eletricidade.

Os benefícios da inserção da energia eólica para a segurança da matriz elétrica brasileira são importantes devido à sua complementaridade com o regime hídrico e manutenção do caráter 
limpo e renovável da matriz energética brasileira (Rampinelli e Rosa Júnior, 2012). O caráter renovável e o fato de não lançar poluentes para a atmosfera durante sua operação tornam a energia eólica uma das fontes mais promissoras para mitigação de problemas ambientais tanto a nível global como nacional. Entretanto, a energia eólica, como qualquer outra atividade industrial, também pode causar impactos no ambiente que devem ser considerados e mitigados (Amponsah et al., 2014).

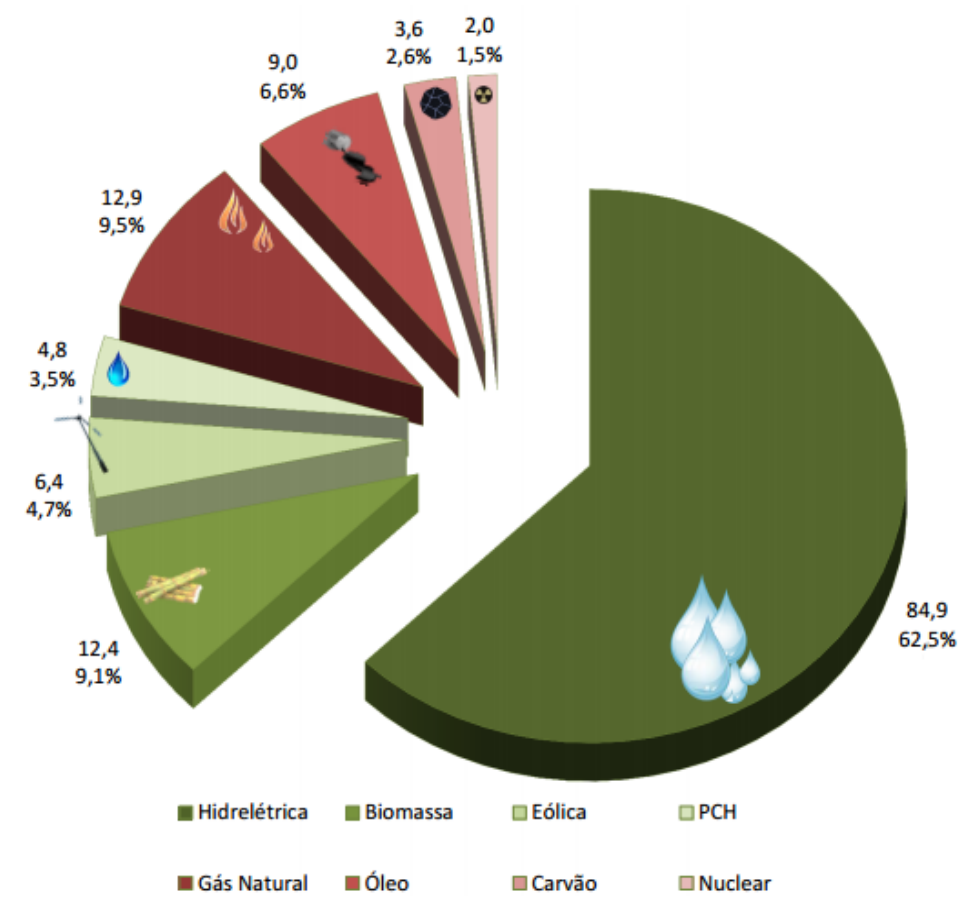

Figura 1. Matriz Elétrica Brasileira (GW) em abril 2015, por fonte de combustível. A participação da energia eólica atingiu participação superior às algumas fontes convencionais de geração de eletricidade incluindo a energia nuclear, o carvão e pequenas centrais hidroelétricas. Neste momento, a participação da energia eólica equivalia a cerca da metade da participação do gás natural.

Fonte: ABEEólica (2015).

Uma barreira que inicialmente se apresentou para a expansão de fontes renováveis e alternativas no Brasil é a preocupação com maior custo de geração por elas apresentado que é conflitante com a necessidade de modicidade tarifária. Frente à política de expansão energética brasileira e da crescente inserção de fontes renováveis, principalmente a eólica, entende-se que o sistema está passando por um processo de adaptação (Jong et al., 2015; Schmidt et al., 2016). Este artigo tem por objetivo discutir o setor eólico brasileiro, com base na revisão das publicações de impacto para o setor energético, incluindo políticas públicas de incentivo adotadas e os impactos sociais e ambientais que estão se apresentando para o país. Em razão da curta história do aproveitamento do recurso eólico na geração de eletricidade no Brasil, há a necessidade de promover a disseminação do conhecimento adquirido e instigar a curiosidade para novas questões que possam dar a sustentabilidade para a expansão da geração de eletricidade a partir da energia dos ventos. 


\section{ENERGIA EÓLICA NO BRASIL}

Os primeiros projetos em energia solar e eólica foram implementados na década de 90 tanto nos estados do Nordeste como também da região norte do Brasil, onde a carência de abastecimento elétrico é uma das mais acentuadas e graves do país. Por apresentar várias comunidades isoladas, não atendidas pelo fornecimento das fontes convencionais de energia, vários projetos foram ali implementados com instalações de sistemas fotovoltaicos e eólicos para geração descentralizada de energia elétrica (Dutra e Szklo, 2008).

O primeiro aerogerador foi instalado no Brasil em 1992 no arquipélago de Fernando de Noronha. Dados recentes mostram que 336 usinas eólicas estão operando no Brasil, totalizando uma potência instalada da ordem de 8195 MW (Banco de Informações de Geração ANEEL 2016). Embora ainda existam divergências entre especialistas na estimativa do potencial eólico brasileiro, vários estudos indicam valores consideráveis para um alto desempenho deste tipo de energia no Brasil (Costa e Lyra, 2012).

Em 2001, foi publicado o Atlas do Potencial Eólico Brasileiro identificando regiões do território brasileiro de grande potencial para o uso de energia eólica (Figura 2.a). Essa publicação mostra que o Brasil possui uma área de aproximadamente $0,8 \%$ de todo o território com ocorrência de ventos com velocidades médias igual ou acima de $7 \mathrm{~m} . \mathrm{s}^{-1}$ ao nível de $50 \mathrm{~m}$ acima do solo, totalizando o potencial de 143,4 GW, capaz de gerar $272 \mathrm{TWh} / \mathrm{ano}$. A maior parte desse potencial eólico está localizada nas regiões nordeste, sudeste e sul (Silva et al., 2005). Outro aspecto observado no Atlas Eólico é a predominância dos ventos favoráveis nas regiões costeiras onde se encontra a maior densidade de linhas de transmissão em função da proximidade de grandes centros urbanos e que aliado à densa malha viária local repercute favoravelmente para redução do custo dos projetos eólicos (Figura 2.b). Vale a pena ser destacado que o potencial eólico brasileiro está subestimado no Atlas Eólico uma vez que a altura dos aerogeradores é superior a $80 \mathrm{~m}$ nos parques eólicos atuais.

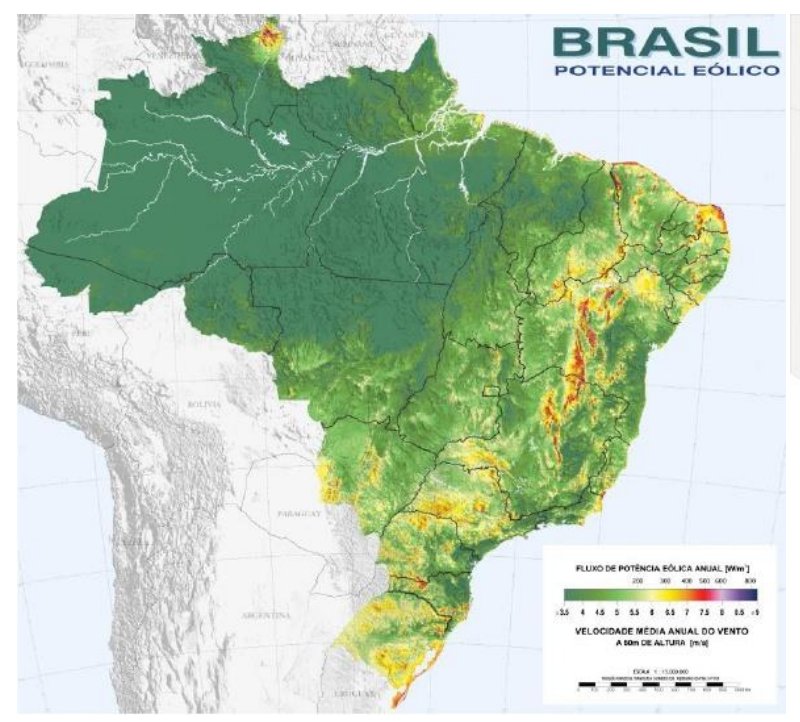

(a)

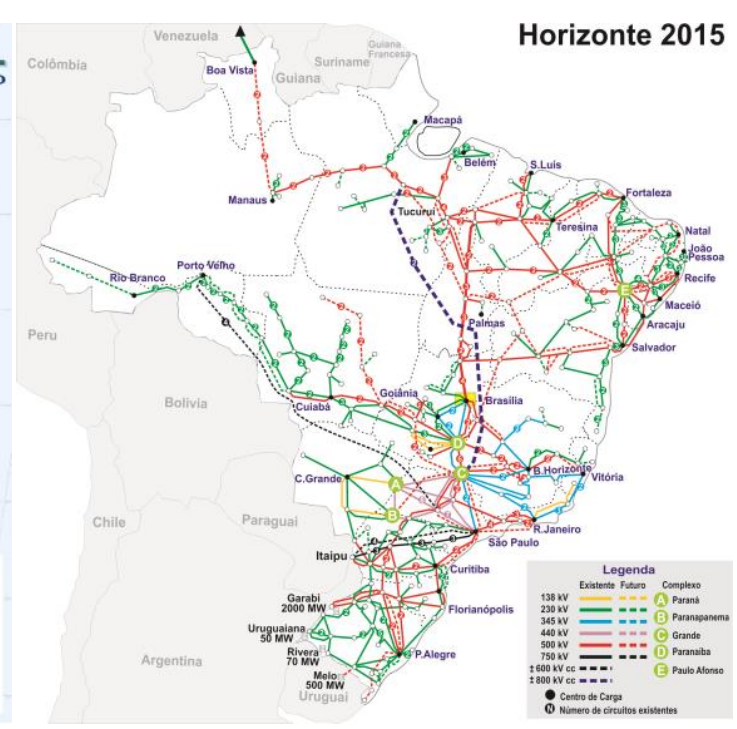

(b)

Figura 2. (a) Mapa do potencial eólico brasileiro. Fonte: Amarante et al. (2001);

(b) Sistema Interligado Nacional (SIN).

Fonte: Operador Nacional do Sistema Elétrico (ONS, 2015).

A pesquisa científica voltada para a energia eólica vem crescendo significativamente, como pode ser comprovado com o número de publicações e eventos técnico-científicos no Brasil nos últimos anos (Costa e Lyra, 2012; Lima et al., 2012; Pottmaier et al., 2013; Ramos et al., 2013; Pinto et al., 2014a). Dentre as várias discussões, nota-se que existe muito consenso 
sobre a importância dessa fonte de energia renovável para o país. No entanto, algumas barreiras se apresentam para a expansão contínua da geração eólica na matriz elétrica nacional. Um dos argumentos básicos contrários está relacionado com a inconstância temporal não controlável e com previsibilidade limitada do recurso eólico e que pode afetar a qualidade da energia distribuída no sistema elétrico (Miranda et al., 2016). Além disso, o potencial eólico sofre influência direta do posicionamento e intensidade dos sistemas de alta e baixa pressão atmosférica que apresentam tanto uma variabilidade interanual quanto variações decadais relacionadas com a variabilidade climática. Esses fatores criam uma barreira negativa para o crescimento da participação do recurso eólico no que diz respeito ao aspecto de segurança energética do sistema elétrico brasileiro.

Com os vários desafios e com os grandes investimentos em pesquisa e desenvolvimento pode-se afirmar que o aproveitamento da energia eólica para geração de eletricidade ainda tem um longo caminho a percorrer, principalmente em países como o Brasil onde os impactos ambientais, sociais e econômicos ainda não são conhecidos com clareza para cada região com potencial favorável deste recurso energético.

\section{RECURSO EÓLICO}

A viabilidade de um projeto de energia eólica está diretamente associada à energia disponível que pode ser extraída do vento e de como esse recurso varia no local do empreendimento. A importância desse aspecto é amplificada pela relação cúbica entre a potência e a velocidade do vento (Burton et al., 2001) descrita pela expressão padrão (Equação 1):

$\mathrm{P}=\frac{1}{2} C_{p} \rho A \mathrm{v}^{3}$

Onde:

$\boldsymbol{\rho}$ é a massa específica do ar $\left(1,225 \mathrm{~kg} / \mathrm{m}^{3}\right)$,

$\mathbf{C}_{\mathbf{p}}$ é o coeficiente de potência,

A é a área varrida pelas pás do rotor, $\mathrm{e}$

$\mathbf{v}$ é a velocidade do vento.

É importante destacar que na equação 1 não está sendo considerada a eficiência do aerogerador.

A variabilidade temporal e espacial do vento depende de fatores como a complexidade da topografia e do clima na região que define sazonalidades anuais e diárias. Devido à variabilidade do recurso eólico, o desempenho dos aerogeradores de uma usina eólica, não pode ser avaliado sem adequada aquisição de dados de vento realizadas no local de instalação. Assim, a melhor e mais precisa indicação do recurso disponível num dado local de interesse é obtida através de campanhas de medição no sítio, usando anemômetros e sensores de direção em alturas compatíveis com a altura do eixo do rotor do aerogerador que se deseja instalar (Burton et al., 2001).

Entretanto, esse processo tem um custo elevado em razão da altura da torre dos aerogeradores modernos que, atualmente, variam entre 80 e $120 \mathrm{~m}$, e da necessidade de campanhas de medição de vento por um período mínimo de 2 a 3 anos para atender os requisitos de confiabilidade impostos pelas autoridades permissionárias locais e das agências de financiamento. No Brasil, um período contínuo de medição de 1 ano era um requisito mínimo necessário para habilitação da participação de projetos eólicos em leilões de compra de energia elétrica realizados pela ANEEL (Agência Nacional de Energia Elétrica) e a Câmara de 
Comercialização de Energia Elétrica (CCEE) até 2011. A partir desse ano, o período foi estendido para 2 anos de coleta de dados de vento para os leilões seguintes. Essa decisão provavelmente foi influenciada pelo o fato de alguns parques eólicos do PROINFA (Programa de Incentivo às Fontes Alternativas de Energia Elétrica) terem apresentado uma geração anual de energia abaixo do projetado em 2009 e 2010 (Ramos et al., 2013).

Em virtude dos gastos e esforços necessários para realização de uma coleta de dados de vento com precisão adequada, que permita uma avaliação confiável do potencial eólico em um sítio, os modelos numéricos vêm sendo usados para estimar e prever o recurso a nível nacional e regional. Nos últimos anos diversos estudos estão sendo publicados com o objetivo de aprimorar os modelos meteorológicos regionais utilizados para estimativa do vento (Giorgi et al., 2011; Pinto et al., 2012; Cheng et al., 2013; Ramos et al., 2013; Mattar e Borvarán, 2016). Os modelos têm se mostrado uma ferramenta importante e confiável que demanda um investimento relativamente baixo (Martins et al., 2008; Monteiro et al., 2009). Deve-se ressaltar que a modelagem numérica não substitui as medições de vento no local e, ao invés disso, servem para indicar quais locais merecem uma avaliação mais detalhada para realização de campanhas de medição de custo elevado e para prover previsões de geração eólica em diferentes escalas de tempo.

\section{POLÍTICAS PÚBLICAS}

No ano de 1994 realizou-se, em Belo Horizonte/MG, o I Encontro para Definição de Diretrizes para o Desenvolvimento de Energia Solar e Eólica promovido pelo Ministério de Minas e Energia (MME) e Ministério de Ciência e Tecnologia (MCT). Foram elaborados naquela ocasião, metas e diretrizes, em reunião plenária com 120 participantes de 79 entidades, formulando, como resultado final, a chamada "Declaração de Belo Horizonte".

Em consequência da declaração, nesse mesmo ano, foi instalado o primeiro parque eólico de Morro do Camelinho interligada à rede localizado no município de Gouveia/MG, e composto de 4 aerogeradores de $250 \mathrm{~kW}$. A primeira usina de energia eólica (UEE Mucuripe) começou a funcionar no nordeste brasileiro (NEB) em 1996 na cidade de Fortaleza/CE com potência instalada de $1200 \mathrm{~kW}$. Esses dois empreendimentos foram cruciais para incentivar o crescimento da geração de energia eólica no Brasil. Logo após, começaram a surgir os primeiros mapeamentos estaduais e nacionais do potencial eólico que impulsionaram a adoção de políticas para incentivo à instalação de novos parques nos anos seguintes. A potência eólica instalada atingiu 26,7 MW em 2005.

O primeiro programa de larga escala para incentivo ao desenvolvimento da energia eólica no Brasil foi o PROEÓLICA (Programa Emergencial de Energia Eólica) iniciado em 2001 como resposta do governo à crise energética que o país vinha enfrentando em razão do reduzido regime pluviométrico registrado e consequente baixo armazenamento de água nos reservatórios das hidroelétricas nacionais. Através deste programa, a energia eólica recebeu um incentivo adicional sobre o preço de compra por kWh. O programa instituía a implantação de $1050 \mathrm{MW}$ a serem instalados até o fim de 2003. O PROEÓLICA gerou uma corrida de investidores para iniciar o processo de homologação de seus projetos eólicos junto a ANEEL e, junto com esse processo, então surgiram às primeiras barreiras. Na época havia apenas um fornecedor de equipamentos eólicos instalado no Brasil, assim os investidores identificaram a necessidade de importação de tecnologia e também formação de mão de obra qualificada para estes tipos de empreendimentos.

A experiência adquirida pelo PROEÓLICA serviu como base para os programas governamentais de incentivo às fontes renováveis em nível nacional e estadual que foram implantados na sequência com o intuito de promover a diversificação da matriz energética brasileira. O PROINFA foi um programa governamental elaborado no âmbito do MME, e 
implementado pela Lei $\mathrm{n}^{\circ} 10.438$, de 26 de abril de 2002 e revisado, posteriormente, pela Lei $\mathrm{n}^{\mathrm{o}}$ 10.762, de 11 de novembro de 2003. Decisões políticas como o PROINFA foram fundamentais para viabilizar o mercado de energia eólica no Brasil.

Por meio desses incentivos e de uma série de ações institucionais adotadas para facilitar a implementação de novos projetos, a participação da energia eólica cresceu rapidamente na matriz elétrica do Brasil. A realização de leilões de energia específicos para geração eólica é uma iniciativa recente que resultou do novo modelo adotado para o setor elétrico. A cada ano, o país precisa contratar mais fontes de energia para atender à demanda crescente de eletricidade e os leilões servem para unir geradores de energia e distribuidoras. Os leilões de energia funcionam de maneira reversa ao que ocorre em um leilão típico. Ele é iniciado com um preço máximo e vai decrescendo ao longo do processo. A ANEEL é a instituição responsável pela condução dos procedimentos licitatórios. O custo da energia eólica no início da vigência do PROINFA atingiu valores da ordem de $\mathrm{R} \$ 298,00 / \mathrm{MWh}$. Esses valores eram muito superiores ao custo das fontes convencionais de energia, que estavam na faixa de R \$100,00 /MWh. Entretanto, devido aos incentivos governamentais, o custo da geração eólica foi reduzido consideravelmente, fato que possibilitou a chegada de empresas multinacionais de energia que, devido à crise mundial de 2008 e à necessidade de expansão das atividades para novos mercados, investiram fortemente no Brasil com instalação de parques e de fábricas de componentes e aerogeradores para as usinas eólicas (Dutra e Szklo, 2008; Rampinelli e Rosa Júnior, 2012).

Entender o custo da eletricidade requer uma análise cuidadosa de vários fatores. Algumas distribuidoras têm uma composição de compra de energia mais barata do que outras, há áreas de concessão que, devido à grande extensão e à baixa densidade demográfica necessitam de maiores investimentos para atender a cada consumidor. Há redes de distribuição que demandam procedimentos de manutenção com maior complexidade tornando os custos operacionais distintos e, finalmente, os impostos estaduais e municipais incidentes sobre as tarifas também oscilam bastante (Ramos et al., 2013). O volume de subsídios incluídos na tarifa (subsídio para baixa renda, para fontes incentivadas, e para cooperativas) tem importância variada entre as diversas distribuidoras.

Dados do MME (Brasil, 2016) mostram que, no ano de 2015, a geração eólica apresentou segundo menor custo do MWh (R $\$ 191,00$ por Megawatt-hora) sendo superior apenas ao custo apresentado pela geração hidrelétrica $(\mathrm{R} \$ 182,00 / \mathrm{MWh})$. No entanto, deve-se considerar que o Brasil ainda apresenta desafios a serem vencidos que afetam o custo da geração eólica. A cadeia de suprimentos ainda se encontra em estágio inicial de desenvolvimento, há escassez de recursos humanos qualificados e com expertise para atuação tanto na pesquisa e desenvolvimento de tecnologia quanto nas diversas fases do ciclo de vida de parques eólicos projeto, instalação, operação e manutenção (Netherlands, 2014). Os dados recentes dos valores apresentados nos leilões de energia mostram um declínio contínuo e robusto do custo de geração eólica, no entanto, alguns especialistas apontam a necessidade de cautela na interpretação dos dados (IRENA, 2012). Estima-se que o custo da geração eólica é inferior ao da geração com uso de fontes convencionais como hidrelétrica e gás natural quando se leva em conta todo o contexto socioambiental de instalação das tecnologias de geração ao longo de todo seu ciclo de vida (Jong et al., 2013; Amponsah et al., 2014).

Nos últimos anos, as usinas termoelétricas alimentadas com combustíveis fósseis vêm sendo utilizadas de forma crescente em procedimentos operacionais emergenciais para abastecimento de energia elétrica em função à queda do nível dos reservatórios das hidrelétricas em diferentes regiões do Brasil. Um exemplo recente é a longa estiagem no território brasileiro ao longo desde 2013 que prolongou o uso de plantas de geração térmica ao longo de todo o período de 2014-2015. A operação das usinas térmicas trouxe impacto significativo tanto para 
a economia nacional em razão do elevado custo da energia elétrica produzida nessas plantas quanto para o balanço das emissões brasileiras de GEE. Para evitar que esta condição continue se repetindo em condições climáticas similares, há necessidade de um planejamento da oferta de energia com base em séries de dados meteorológicos e climáticos confiáveis produzidos para previsão de geração das usinas eólicas a curto e médio prazo (Beluco et al., 2008; Schmidt et al., 2016).

\section{IMPACTOS AMBIENTAIS}

Quando se fala em impactos ambientais da geração eólica, uma das primeiras questões discutidas é com relação as emissões de GEE. As emissões do setor de energia cresceram 33,4 Mt $\mathrm{CO}_{2}$ e entre 2012 e 2013, aproximadamente 8,0\%. O forte crescimento das emissões do setor de energia, aliado ao decréscimo das taxas de desmatamento na Amazônia (PRODES, 2015) e das emissões devidas às alterações do ouso da terra, modificou significativamente a participação de cada setor no total das emissões brasileiras ao longo do período estudado. A contribuição do setor de energia passou de $11 \%$ das emissões em 2003 para $29 \%$ em 2013. A medida que as taxas de desmatamento continuam a ser reduzidas, o setor de energia tende a figurar entre os mais importantes em termos de emissões de GEE (Azevedo et al., 2017), principalmente se aumentar a geração de energia por meio de termoelétricas, como aconteceu nos anos de 2014 e 2015.

Assim como uma das tecnologias mais maduras dentre as fontes renováveis, a energia eólica tem visto seu crescimento acelerado durante a última década no Brasil. Ela tornou-se a principal opção para os planejadores e os governos nacionais, que procuram diversificar os recursos energéticos e reduzir as emissões de $\mathrm{CO}_{2}$, fomentar novas indústrias, e gerar novas oportunidades de emprego (Azevedo et al., 2017).

Os impactos ambientais associados à energia eólica possuem um caráter bastante específico e fortemente dependente da localização selecionada para a instalação do parque eólico. $\mathrm{Na}$ Europa, onde existe maior experiência com a operação de parques eólicos, estudos mostram que os impactos considerados mais críticos são: impacto visual (estético), ruído acústico e os impactos sobre a fauna (Burton et al., 2001). Porém, esses impactos vêm sendo questionados no Brasil, onde os problemas ambientais encontrados são diferentes aos da Europa e Estados Unidos. Por exemplo, a usina de energia eólica de Taíba (município de São Gonçalo do Amarante/CE), composta por 10 aerogeradores de 45 metros de altura, foi à primeira do mundo a ser construída sobre dunas de areias no ano de 1999.

A etapa de construção é a fase crítica em termos de impactos socioambientais produzidos por uma planta de geração eólica. Entretanto, os impactos negativos durante a instalação são relativamente pequenos quando comparados com aqueles produzidos por fontes convencionais de energia, como a usina hidroelétrica que demandam grandes obras de construção civil. Mesmo assim, os impactos ainda devem ser avaliados e mitigados quando possível (Montezano, 2012; Amponsah et al., 2014) através de planejamento adequado e também da aplicação de novas tecnologias (Dutra e Szklo, 2008).

\subsection{Impacto visual e sobre a paisagem}

O conceito de paisagem apresenta entendimentos e definições diversas. Estudos apontam que a paisagem aparece identificada desde o século $18 \mathrm{com}$ a fisionomia de uma dada área e associada às suas características físicas, traduzida na combinação local dos elementos naturais e humanos (Salgueiro, 2001). Desde o século 20, a geografia humana passa a entender a paisagem como um território visto e sentido, cada vez mais subjetivo e elaborado pela mente humana. Neste sentido, a discussão dos impactos visuais produzidos pela ação humana é bastante controversa e dependente de características regionais. O elemento subjetivo incide 
sobre a formulação do conceito do que possa vir a ser classificado como desagradável e agressivo ao olhar (Silva, 2003).

A reação provocada por um parque eólico é altamente subjetiva. Muitas pessoas olham a turbina eólica como um símbolo de energia limpa e avanço tecnológico, outras reagem negativamente à nova paisagem. Por isso a percepção da paisagem e o impacto visual são considerados questões chave na localização de parques eólicos pelas suas características subjetivas e variáveis ao longo do tempo e do espaço territorial. Estudos mostram que o impacto visual pode ser a principal influência sobre a atitude pública em relação a parques eólicos em razão da percepção estética atribuída aos aerogeradores (Wolsink, 2000; Rodman e Meentenmeyer, 2006).

Os aerogeradores modernos são estruturas grandes, atingindo $150 \mathrm{~m}$ de altura desde a base da torre até a ponta da pá (Figura 3), e são colocados, em geral, em locais de relevo pouco complexo, com poucos obstáculos e com grande visibilidade. Os parques eólicos são implantados em áreas com poucos obstáculos e em elevações naturais do relevo - condições ambientais típicas associadas com velocidades de vento elevadas e que possibilitam uma visibilidade a grandes distâncias. Os aerogeradores devem ser espaçados de pelo menos 3 a 5 vezes o diâmetro de seu rotor, o que faz com que parques eólicos de grande porte ocupem áreas extensas. O tamanho dos aerogeradores somado ao movimento giratório das pás tem o potencial de atrair atenção das pessoas de modo que parques eólicos podem se tornar pontos dominantes na paisagem (Burton et al., 2001).

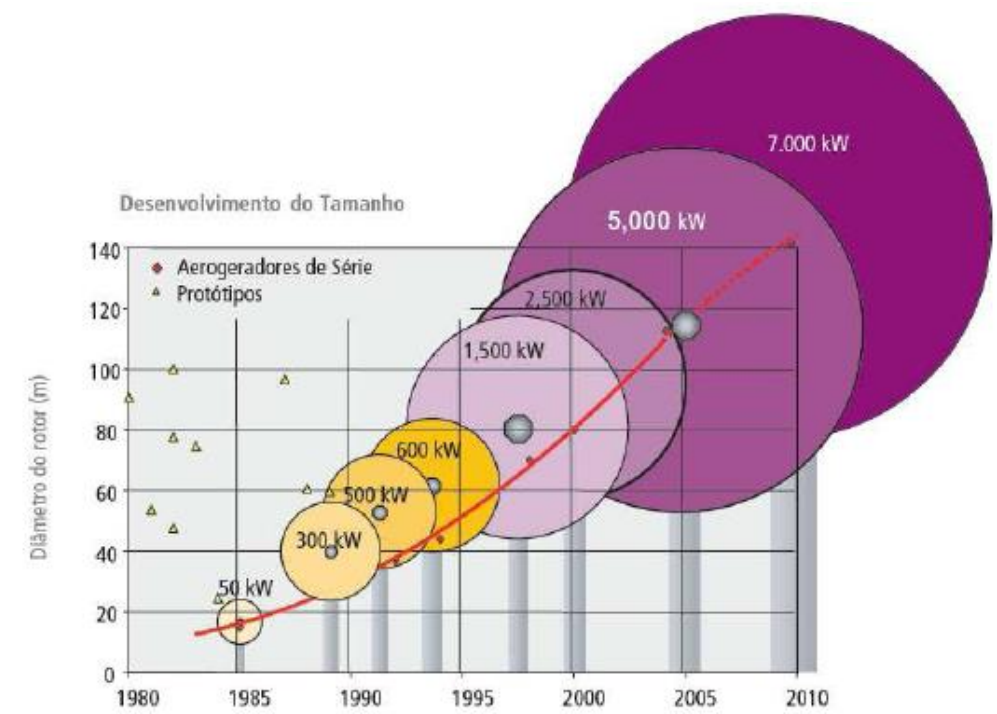

Figura 3. Evolução tecnológica dos aerogeradores ao longo das últimas três décadas.

Fonte: adaptado Cepel (2013).

As características dos empreendimentos eólicos que podem causar efeitos na paisagem incluem: o tamanho, altura, número, material e cor dos aerogeradores, pista de acesso e conexão do sítio, edificações da subestação, conexão à rede, torres anemométricas e linhas de transmissão. Em um estudo financiado pelo governo dos Estados Unidos, 377 observações de cinco instalações de vento em Wyoming e Colorado foram feitas sob várias condições de iluminação e tempo. As instalações foram classificadas como visíveis a olho nu em distâncias inferiores a $58 \mathrm{~km}$ sob condições de visualização ideais. O movimento das pás da turbina foi frequentemente identificado como visível em distâncias inferiores a $39 \mathrm{~km}$. 
Dois trabalhos publicados pela comunidade internacional destacam a importância do tema internacionalmente. O primeiro estudo foi elaborado pela Universidade de Newcastle e propõe diretrizes para localização de aerogeradores e avaliação da zona de influência de parques eólicos operando na Escócia (Buchan, 2002). Vissering et al. (2011) propôs uma metodologia eficaz e objetiva de avaliação de impacto estético que fornece orientação clara para a academia, tomadores de decisão e órgãos reguladores. Este último estudo também visa a proteção de importantes recursos cênicos e culturais em locais propícios para o aproveitamento do recurso eólico. Uma característica bastante favorável dos parques eólicos é a característica transiente, de modo que a área utilizada pode ser restaurada a condição original após a fase de descomissionamento e reintegração.

No âmbito da geração eólica, o efeito visual destes empreendimentos é contrabalanceado com os impactos associados a diminuição de GEE e outros efeitos degradativos provocados pela geração a partir de fontes de energia convencionais (termoelétricas, nuclear, hidroelétricas). Assim, os parques eólicos são, em geral, aceitos pela maioria da população como parte da paisagem local. Este fato foi constatado em algumas pesquisas como a realizada no Reino Unido onde foram entrevistadas 134 pessoas que residem próximo a parques eólicos e metade das respostas mostraram fortes convicções quanto ao aspecto positivo da paisagem dos parques e a outra metade foi positiva com algumas reservas (Esslemont e Moccormick, 1996).

No Brasil, questionamentos quanto ao impacto visual vêm sendo levantados por ambientalistas e pesquisadores em razão do número significativo de empreendimentos instalados ou em instalação em dunas de areias e outros pontos de grande interesse turístico (Pinto et al., 2014b). As dunas possuem características dinâmicas que produzem movimentação ao longo dos dias, meses e anos. Com a implantação de parques eólicos esta migração natural pode ser alterada ou, na pior condição, parar de acontecer, ocasionando diversos problemas ambientais (Meireles, 2011). A alteração paisagística causada pela presença dos aerogeradores pode causar uma desvalorização monetária da região, atingindo a economia local com a redução do valor dos imóveis e redução da atividade turística. Isto ocorre mais comumente na região litorânea, por serem áreas de lazer e veraneio. Por outro lado, como estética implica em subjetividade, podem ocorrer situações em que um parque eólico se transforma em atração turística, devido a sua "imponência” e "indicação de desenvolvimento tecnológico".

\subsection{Impacto do ruído}

O impacto ambiental do ruído gerado pelo sistema eólico ao girar as pás foi um dos mais importantes temas de discussão e bloqueio da disseminação da energia eólica durante os anos 80 e início dos anos 90. O desenvolvimento tecnológico na última década, juntamente com as novas exigências de mercado, promoveram um avanço significativo na diminuição dos níveis de ruído produzidos pelos empreendimentos de geração de energia eólica. Ao contrário do impacto visual e alteração da paisagem, o ruído acústico pode ser medido e facilmente previsto.

Os ruídos produzidos pelo aerogeradores costumam ser classificados em dois tipos: ruído mecânico proveniente das caixas de engrenagens e gerador, e ruído aerodinâmico proveniente das pás. Os aerogeradores modernos tem praticamente eliminado o ruído acústico através do isolamento acústico da nacele (estrutura onde o gerador fica localizado no alto da torre de um aerogerador), portanto o ruído aerodinâmico é o maior contribuinte.

O ruído aerodinâmico é produzido pela rotação das pás em atrito com o ar gerando um ruído sonoro de amplo espectro de frequências e é função da velocidade de ponta de pá. Os aerogeradores modernos têm sido otimizados para reduzir o ruído aerodinâmico reduzindo a velocidade de rotação e usando controles de passo da potência gerada (Montezano, 2012). A American Wind Energy Association (AWEA) realizou um estudo revelando que, com uma 
distância de 350 m da turbina, o ruído é próximo de 35 a 45 decibéis (Figura 4), inferior ao ruído observado em ambientes de escritório (Ricosti, 2011).

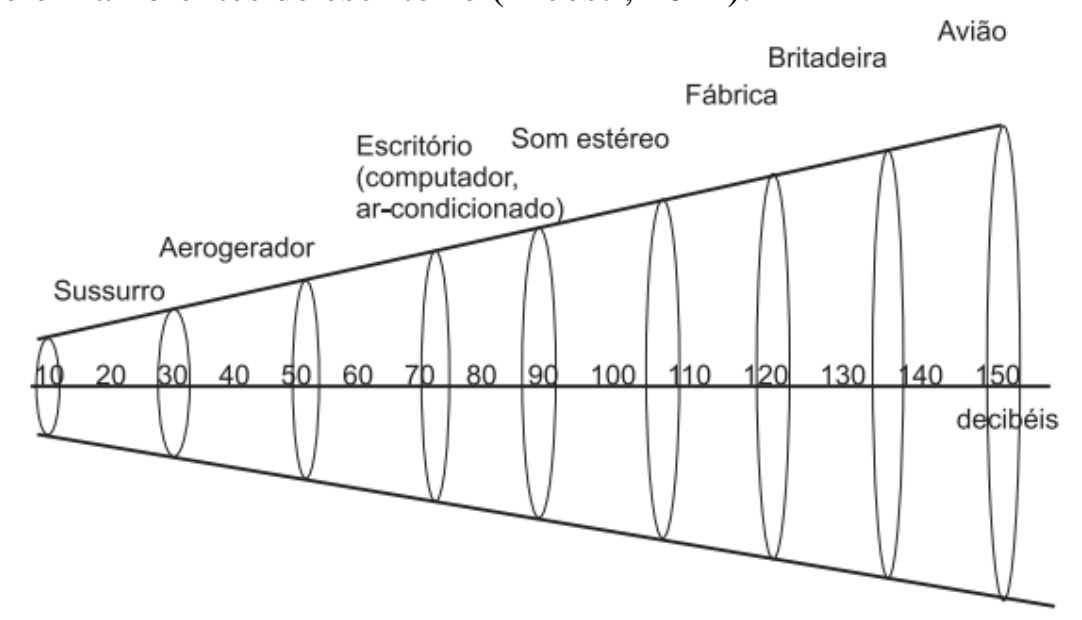

Figura 4. Nível de ruído de diversas atividades.

Fonte: Elaborado com base em Global Wind Energy Council (GWEC).

\subsection{Interferências eletromagnéticas}

A operação de parques eólicos pode provocar a ocorrência de interferências eletromagnéticas causando perturbações nas comunicações e transmissões de dados (rádio, televisão, etc.). Elas variam com as especificações geográficas do local e com o material utilizado no aerogerador (Ricosti, 2011). Sistemas de comunicação modernos podem ter seus sinais comprometidos por aerogeradores, em particular, nos empreendimentos eólicos que estão localizados no topo de morros e locais abertos que oferecem uma alta produção de energia para parques eólicos e bons caminhos de propagação para sinais de comunicação. A interação de aerogeradores com radares civis e de defesa usados para controle de tráfego aéreo também tem sido assunto de investigação (Burton et al., 2001).

A interferência eletromagnética pode ser produzida por três elementos do aerogerador: a torre, a rotação das pás e o gerador. As torres podem obstruir refletir ou refratar as ondas eletromagnéticas. Entretanto, as pás modernas são feitas tipicamente de materiais sintéticos (por exemplo, fibra de vidro) que possuem um impacto mínimo na transmissão de radiação eletromagnética. A possível interferência do sistema elétrico pode ser facilmente eliminada com o isolamento apropriado da nacele e boa manutenção. A interferência com serviços de radiocomunicação móvel é normalmente desprezível e com sinais de TV tem sido minimizada com a substituição das pás de metal por material sintético. Entretanto, quando os aerogeradores são instalados próximos de áreas residenciais, a interferência tem se mostrado mais difícil de eliminar.

A área de interferência pode ser facilmente determinada usando a Zona de Fresnel de forma que medidas técnicas de mitigação para interferência eletromagnética podem ser aplicadas durante a fase de planejamento e projeto do parque eólico, localizando o aerogerador longe da linha de visão do transmissor de radiodifusão. Nos casos em que o parque eólico já esteja em operação, existe um conjunto de medidas técnicas que podem mitigar a interferência. Desse modo, é senso comum que o projeto e a localização adequados podem evitar ou corrigir qualquer possível problema interferência eletromagnética.

\subsection{Impacto em aves}

Esta questão é atualmente bastante controversa e há estudos que apresentam conclusões conflitantes. Vários trabalhos científicos argumentam que aerogeradores poderiam aumentar a mortalidade de aves, porém este fato está relacionado principalmente com os primeiros parques 
eólicos, para os quais não se exigia um estudo de rotas migratórias de aves antes da sua instalação. Diversos estudos indicando taxas de mortalidade de aves similares estão citados por Van Kooten em relatório publicado em 2015 (Van Kooten, 2015). O parque eólico Altamont Pass localizado na Califórnia/EUA, com grande número de aerogeradores de pequeno porte, é citado frequentemente e tornou-se conhecido mundialmente por apresentar valores elevados de morte de aves. No entanto, os aerogeradores foram substituídos recentemente por equipamentos mais modernos com o intuito de mitigar o impacto sobre as aves.

Ricosti (2011) apresenta estimativas elaboradas em diversas regiões do planeta. Para os Estados Unidos, Ricosti menciona estimativas em que o número de aves mortas por MW instalado de capacidade eólica varia entre uma e seis por ano, o que é considerado insignificante. Trata-se de valor inferior a $0,1 \%$ (Figura 5) das mortes não naturais de aves no país. Estatísticas levantadas na Espanha com amostra de mil turbinas mostraram que a taxa de mortalidade de aves está entre 0,1 e 0,6 por turbina ao ano. Estudos realizados na Alemanha, Dinamarca e Holanda, em parques que operam há muito anos, não registraram mudança importante no número de aves e espécies desde a instalação dos aerogeradores. Apesar dos baixos valores observados, alguns parques vêm instalando estímulos visuais e auditivos nas torres eólicas para reduzir ainda mais esta taxa evitando a colisão de aves.

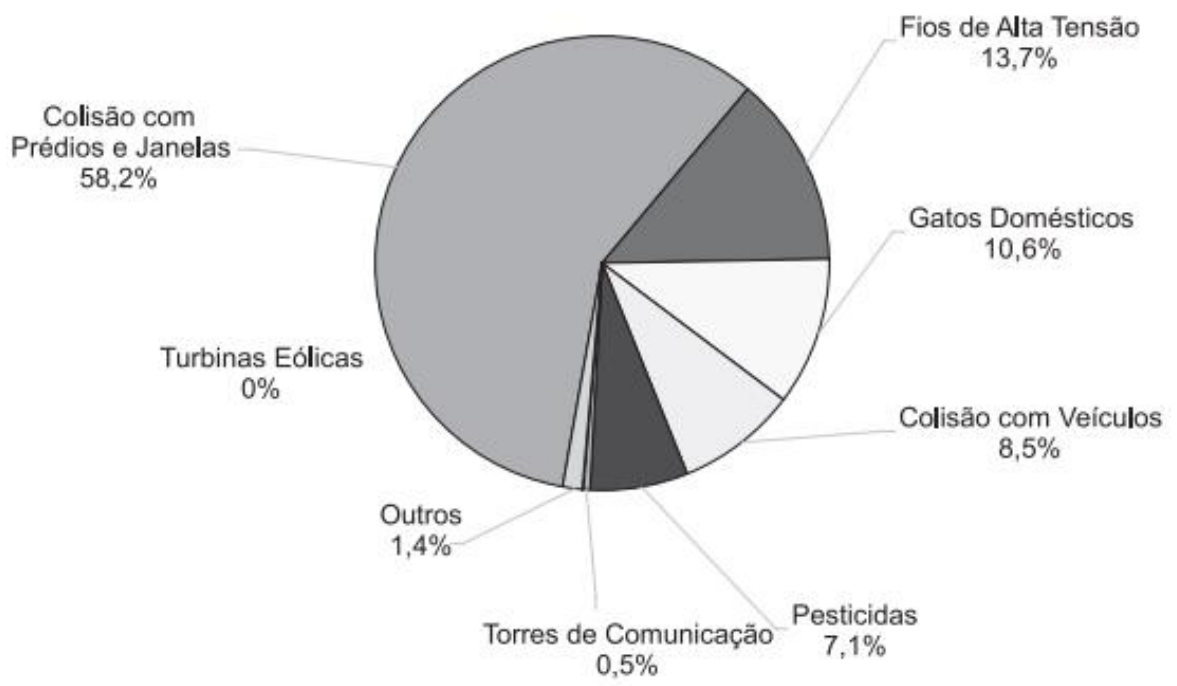

Figura 5. Causa de morte de aves relativas a atividades humanas nos Estados Unidos.

Fonte: AWEA (apud Ricosti, 2011).

Medidas de mitigação para esse impacto dependem do local onde o parque eólico está instalado e das espécies observadas na região. No entanto, algumas das ações mitigadoras são comuns para todo empreendimento eólico, independente da região:

- importantes zonas de conservação e áreas de sensibilidade devem ser evitadas;

- um programa de monitoramento ambiental antes, durante e depois da construção vai fornecer a informação necessária para avaliar o impacto sobre as aves;

- projeto adequado de parques eólicos: situando aerogeradores próximos e agrupando aerogeradores para evitar um alinhamento perpendicular às trajetórias principais de voo das espécies nativas e migratórias;

- providenciar corredores livres entre grupos de aerogeradores, quando necessário;

- aumentar a visibilidade das pás do rotor; 
- instalação de cabos de transmissão subterrâneos;

- treinamento ambiental adequada para equipe de trabalhadores do parque eólico;

- presença de especialistas ambientais durante a construção em localidades sensíveis;

- realocação de aerogeradores conflitantes;

- interrupção da operação durante os períodos de migração; e

- redução da velocidade rotor durante períodos críticos.

\section{IMPACTOS SOCIAIS}

A relação intrínseca entre o consumo de energia e o desenvolvimento social de uma região é consequência do aprimoramento da infraestrutura para oferta de serviços essenciais (educação, saúde, atividades culturais e entretenimento) para crescimento do padrão de vida da população de uma região (Goldemberg e Lucon, 2008). Nesse sentido, o aproveitamento da energia eólica para geração de eletricidade é um importante vetor de desenvolvimento social, principalmente se utilizado para atendimento de comunidades isoladas e da erradicação de bolsões de miséria em regiões de maior vulnerabilidade social, permitindo a universalização do uso da energia a custos menores, geração de empregos (Simas e Pacca, 2013), além de consequente redução do êxodo rural, uma das maiores causas da pobreza e da marginalização em áreas urbanas do país.

No entanto, decisões sobre a localização de parques eólicos devem ser tomadas levando em consideração também os usos da terra na região de interesse. A localização de parques eólicos em áreas de preservação e áreas destinadas ao atendimento de comunidades indígenas devem ser evitadas de forma a evitar impactos similares aos observados em grandes centrais hidrelétricas (Fearnside, 2013). Esse tipo de planejamento deve ser alinhado com as perspectivas e políticas de expansão da energia eólica no país e com a definição de um zoneamento ecológico-econômico para energia eólica (Barbosa Filho e Azevedo, 2014).

\subsection{Ocupação e uso da terra}

Os procedimentos administrativos necessários para aprovar parques eólicos para cada sítio devem ser levados em consideração desde a etapa inicial do processo de planejamento do parque eólico. Tomadores de decisão locais e regionais devem decidir se um projeto é compatível com os usos do solo existentes e planejados nas áreas adjacentes ao parque eólico. A investigação deve avaliar se o aproveitamento eólico poderá modificar a característica da área circunvizinha prejudicando as atividades socioeconômicas e culturais das comunidades estabelecidas, e se estará integrada à paisagem existente (Pinto et al., 2014b). Desde o estágio inicial do planejamento, os empreendedores devem manter um diálogo com os diversos agentes envolvidos na área: Ministério da Defesa, autoridades da aviação civil, provedores de comunicação de rádio e radar, concessionária de eletricidade local, autoridades de proteção ambiental, entidades de representação das comunidades locais e associações não governamentais relevantes, entre outras.

Existem alguns trabalhos que apontaram para um crescimento excessivo de usinas eólicas instaladas em área de preservação permanente com ocupação de dunas de areias no NEB sem que um monitoramento integrado tenha sido realizado para avaliação dos impactos cumulativos nessas áreas. As intervenções foram realizadas, abrangendo campo de dunas fixas e móveis, lagoas interdunares (sazonais), planície de aspersão eólica, manguezais e faixa de praia. Esses empreendimentos podem estar impactando significativamente os ecossistemas associados às matas de duna e tabuleiro e, possivelmente, a dinâmica do lençol freático (Meireles, 2011).

A interação entre o turismo e empreendimentos eólicos é um aspecto de grande importância do ponto de vista social. Geralmente as áreas turísticas são localizadas em 
paisagens de beleza cênica e/ou de tranquilidade e a presença de parques eólicos poderia reduzir a atratividade do cenário natural. Os questionamentos que relacionam o turismo aos empreendimentos eólicos no Brasil ainda são recentes, mas já há alguns estudos que abordam esta temática. Goldani (2013) verificou a possibilidade de um parque eólico ser inserido como produto turístico e assim um incremento do turismo no município de Osório/RS.

Ainda com relação a ocupação de dunas, o aspecto turístico deve ser considerado uma vez que representam o principal cartão postal em vários municípios do NEB, com grande procura pela beleza natural e para atividades de recreação. Assim, as dunas representam um aspecto de orgulho local com estímulo para preservação e movimentação econômica. A instalação de parques eólicos em áreas de dunas pode alterar a paisagem e a economia das comunidades próximas aos empreendimentos como, por exemplo, a pesca, extração do sal e etc. Há casos em que se observou a comunidade dividida uma vez que reconhecem os benefícios do empreendimento sob o ponto de vista de infraestrutura local (Araújo, 2014).

Atenção especial também deve ser dada ao aproveitamento do recurso eólico em reservas naturais, áreas vizinhas e habitat de alto valor para conservação natural. O Brasil possui áreas protegidas consideradas ricas em biodiversidade e beleza cênica, criadas por Decreto Presidencial ou Lei, denominada de Unidades de Conservação (UC). Em UC de proteção integral não é possível o desenvolvimento de empreendimentos eólicos, mas no caso das UC de uso sustentável, essa possibilidade pode ser avaliada e autorizada pelo ICMBio (Instituto Chico Mendes de Conservação da Biodiversidade) considerando que o aproveitamento eólico seja compatível com a natureza e características da UC em consideração (Montezano, 2012).

Algumas regiões do bioma Caatinga também apresentam ventos favoráveis para geração de energia eólica, principalmente na região central da Bahia. Um exemplo é o Boqueirão da Onça onde projetos foram apresentados para instalação de usinas eólicas como parte do PROINFA. É uma região de mais de um milhão de hectares de vegetação nativa bem conservada, com poucos povoados humanos e uma biodiversidade muito grande para os padrões do semiárido brasileiro. No entanto, pesquisadores temem que esse santuário de conservação possa estar ameaçado pela expansão dos parques eólicos na região (Pacheco e Santos, 2012).

Com o crescimento da participação da energia eólica na matriz elétrica brasileira, torna-se importante compreender a experiência e conhecimento adquiridos ao longo do tempo em outras regiões. A European Wind Energy Association (EWEA) resume as conclusões levantadas por um estudo recente, realizado pelo governo escocês, que analisou e revisou 40 estudos da Europa, Estados Unidos e Austrália sobre os impactos de parques eólicos na indústria do turismo (EWEA, 2009):

- a oposição social ocorre com maior intensidade na etapa de planejamento e projeto do parque eólico;

- um número significativo de pessoas acreditam que existe uma perda de valor cênico quando parques eólicos são instalados; entretanto, para outras pessoas parques eólicos realçam a beleza da área;

- a aceitação dos parques eólicos cresce após a instalação;

- não há evidência que possa sugerir um impacto negativo grave ao turismo.

A EWEA (2009) recomenda que a análise dos impactos sobre o turismo, incluindo a análise do fluxo de turistas na região onde se encontra a usina eólica, seja incluído como parte da análise de impacto ambiental realizada durante o planejamento e projeto dos parques eólicos. 


\section{CONSIDERAÇÕES FINAIS}

A preocupação com a segurança energética e o impacto ambiental decorrentes da expansão do consumo de eletricidade vêm induzindo a diversificação da matriz energética brasileira com o aproveitamento de fontes alternativas de energia renovável.

O Brasil vem ampliando significativamente a participação da geração eólica na sua matriz elétrica como consequência de políticas específicas para o setor. A contribuição da energia eólica cresceu de participação inexpressiva para uma posição de destaque na matriz elétrica nacional ao longo da última década, por ser uma fonte com grande potencial no território brasileiro e não emissora de poluentes e GEE após início da operação.

Embora o recurso eólico contribua com participação da ordem de $6 \%$ da matriz elétrica nacional, muitos novos projetos já estão em fase de conclusão e ainda há um grande potencial inexplorado no país. O PROINFA foi o mecanismo de incentivo mais importante para a energia eólica e, atualmente, empreendimentos de geração eólica vem participando de forma competitiva nos Leilões de Compra de Energia realizados pela ANEEL, sendo que novos parques eólicos estão autorizados para implantação, principalmente nas regiões nordeste e sul do Brasil.

Além dos aspectos financeiros e técnicos, a definição da localização de parques eólicos envolve também questões socioambientais que podem restringir a área disponível e levar inevitavelmente a conflitos associados à forma como o processo de implantação do parque eólico é conduzido. Os parques eólicos, além de serem economicamente viáveis, devem ter um impacto reduzido no ambiente local em termos de intrusão visual, acústica, social, interferência eletromagnética e ecossistema natural. Diante da perspectiva de expansão da geração eólica no Brasil, esses conflitos tendem a se intensificar naturalmente com a ocupação de áreas mais sensíveis do ponto de vista ambiental e social com aerogeradores de grande porte.

Em termos estratégicos, a ampliação do número de parques eólicos, principalmente no NEB, possibilitará a complementaridade eólico-hídrica colaborando para aumento da segurança energética do sistema elétrico brasileiro nos períodos do ano de maior e menor disponibilidade de água nos reservatórios das usinas hidroelétricas. No entanto, em razão da curta história do aproveitamento eólico no Brasil, estudos para avaliação mais aprofundada dos impactos socioambientais devem ser realizados com apoio de recursos do próprio setor energético a fim de promover um crescimento sustentável da participação desta fonte energética na matriz elétrica nacional.

\section{REFERÊNCIAS}

AMARAnTe, O. A. C.; BROWER, M.; ZACK, J.; DE SÁ, A. L. Atlas do Potencial Eólico Brasileiro. Brasília: Ministério de Minas e Energia, 2001. 45 p.

AMPONSAH, N.; TROLDBORG, M.; KINGTON, B.; AALDERS, I.; HOUGH, R. L. Greenhouse gas emissions from renewable energy sources: A review of life cycle considerations. Renewable and Sustainable Energy Reviews, v. 39, p. 461-475, 2014. https://doi.org/10.1016/j.rser.2014.07.087

ARAÚJO, R. C. P. de. Análise da atitude dos turistas com relação ao desenvolvimento da energia eólica no litoral Cearense, Brasil. Turismo \& Sociedade, v. 7, n. 2, p. 308-329, 2014.

ASSOCIAÇÃO BRASILEIRA DE ENERGIA EÓLICA - ABEEÓLICA. Boletim anual de geração, 2015. 
AZEVEDO, J. P. M.; NASCIMENTO, R. S.; SCHRAM, I. B. Energia eólica e os impactos ambientais: um estudo de revisão. Revista UNINGÁ, v. 51, p. 101-106, 2017.

BARBOSA FILHO, W. P.; AZEVEDO, A. C. S. O uso da análise hierárquica como auxílio na tomada de decisão de políticas públicas em energia eólica considerando aspectos de sustentabilidade. In: CONGRESSO DE ENERGIA SOLAR, 5., 2014, Recife. Trabalhos... Recife: ABENS, 2014.

BELUCO, A.; SOUZA, P. K.; KRENZINGER A. A dimensionless index evaluating the time complementarity between solar and hydraulic energies. Renewable Energy, v. 33, $2157-$ 2165, 2008. https://doi.org/10.1016/j.renene.2008.01.019

BRASIL. Ministério de Minas e Energia. Resenha energética brasileira - exercício 2015. Brasília, 2016.

BRASIL. Ministério das Relações Exteriores. INDC - Intended Nationally Determined Contribution. Convenção-Quadro das Nações Unidas sobre Mudança do Clima, 2015. Disponível em: www.itamaraty.gov.br/images/ed_desenvsust/BRASIL-iNDCportugues.pdf

BUCHAN, N. Visual Assessment of windfarms: Best practice. Scottish Natural Heritage Commissioned Report F01AA303A. Callaghan: University of Newcastle, 2002.

BURTON, T.; SHARPE, D.; JENKINS, N.; BOSSANYI, E. Wind Energy Handbook. Chichester: John Wiley \& Sons, 2001.

CENTRO DE PESQUISAS DE ENERGIA ELÁTRICA - CEPEL. As energias solar e eólicas no Brasil. Rio de Janeiro, 2013.

CHENG, W. Y. Y.; YUBAO, L.; YUEWEI, L.; ZHANG, Y.; MAHONEY, W. P.; WARNER, T. T. The impact of model physics on numerical wind forecasts. Renewable Energy, v. 55, p. 347-356, 2013.

COSTA, A. O.; OLIVEIRA, L. B.; LINS, M. P. E.; SILVA, A. C. M.; ARAÚJO, M. S. M.; PEREIRA JÚNIOR, A. O. et al. Sustainability analysis of biodiesel production: A review on different resources in Brazil. Renewable and Sustainable Energy Reviews, v. 27, p. 407-412, 2013. https://doi.org/10.1016/j.rser.2013.06.005

COSTA, G. B.; LYRA, R. F. F. Análise dos padrões de vento no estado de Alagoas. Revista Brasileira de Meteorologia, v. 27, n 1, p. 31-38, 2012.

DUTRA, R. M.; SZKLO, A. S. Incentive policies for promoting wind power production in Brazil: Scenarios for the Alternative Energy Sources Incentive Program (PROINFA) under the New Brazilian electric power sector regulation. Renewable Energy, v. 33, p. 65-76, 2008. https://doi.org/10.1016/j.renene.2007.01.013

ESSLEMONT, E.; MOCCORMICK, M. Sociological impact of a wind farm development. The world directory of renewable energy: suppliers and services. London: Jamesx James, 1996.

EUROPEAN WIND ENERGY ASSOCIATION - EWEA. Wind Energy - The Facts: environmental issues. 2009. Disponível em: http://www.wind-energy-thefacts.org/images/chapter5.pdf/ 
FEARNSIDE, P. M. Viewpoint - Decision Making on Amazon Dams: Politics Trumps Uncertainty in the Madeira River Sediments Controversy. Water Alternatives, v. 6, p. 313-325, 2013.

GIORGI, M. G. de; FICARELLA, A.; TARANTINO, M. Assessment of the benefits of numerical weather predictions in wind power forecasting based on statistical methods. Energy, v. 36, p. 3968-3978, 2011. https://doi.org/10.1016/j.energy.2011.05.006

GOLDANI, A. Turismo e Parque Eólico: possibilidades para o município de Osório (Rio Grande do Sul, Brasil). Turismo \& Sociedade, v. 6, n. 2, p. 424-439, 2013. http://dx.doi.org/10.5380/tes.v6i2.31934

GOLDEMBERG, J. ; LUCON, O. Energia, meio ambiente e desenvolvimento. 3. ed. São Paulo: EDUSP, 2008.

INTERNATIONAL RENEWABLE ENERGY AGENCY - IRENA. 30 years of policies for wind energy: Lessons from 12 wind energy markets. 2012. Disponível em: https://www.irena.org/DocumentDownloads/Publications/IRENA_GWEC_WindReport_Full.pdf/

JONG, P.; KIPERSTOK, A.; TORRES, E. A. Economic and environmental analysis of electricity generation technologies in Brazil. Renewable and Sustainable Energy Reviews, v. 52, p. 725-739, 2015. https://doi.org/10.1016/j.rser.2015.06.064

JONG, P.; SÁNCHES, A. S.; ESQUERRE, K.; KALID, R. A.; TORRES, E. A. Solar and wind energy production in relation to the electricity load curve and hydroelectricity in the northeast region of Brazil. Renewable and Sustainable Energy Reviews, v. 23, p. 526535, 2013. https://doi.org/10.1016/j.rser.2013.01.050

LIMA, F. J. L.; CAVALCANTI, E. P.; de SOUZA, E. P.; SILVA, E. M. Evaluation of the wind power in the state of Paraiba using the mesoscale atmospheric model Brazilian Developments on the Regional Atmospheric Modelling System. Renewable Energy, p. 1-16, 2012. http://dx.doi.org/10.5402/2012/847356

LOAIRE, S. R.; ASNER, G. P.; FIELD, C. B. Boosted carbon emissions from Amazon deforestation. Geophysical Research Letters, v. 36, L14810, 2009. http://dx.doi.org/10.1029/2009GL037526

MALAGUETA, D.; SZKLO, A.; SORIA, R.; DUTRA, R.; SCHAEFFER, R.; BORBA, B. Potential and impacts of Concentrated Solar Power (CSP) integration in the Brazilian electric power system. Renewable Energy, v. 68, p. 223-235, 2014. http://dx.doi.org/10.1016/j.renene.2014.01.050

MARTINS, F. R.; GUARNIERI, R. A.; PEREIRA, E. B. O aproveitamento da energia eólica. Revista Brasileira de Ensino de Física, v. 30, n. 1, p. 1-13, 2008. http://dx.doi.org/10.1590/S1806-11172008000100005

MATTAR, C.; BORVARÁN, D. Offshore wind power simulation by using WRF in the central coast of Chile. Renewable Energy, v. 94, p. 22-31, 2016. https://doi.org/10.1016/j.renene.2016.03.005

MEIRELES, A. J. de A. Danos socioambientais originados pelas usinas eólicas nos campos de dunas do Nordeste Brasileiro e critérios para definição de alternativas locacionais. Revista Franco-Brasileira de Geografia, n. 11, 2011. 
MIRANDA, R.; SORIA, R.; SCHAEFFER, R.; SZKLO, A.; SAPORTA, L. Contributions to the analysis of -Integrating large scale wind power into the electricity grid in the Northeast of Brazil- [Energy 100 (2016) 401-415]. Energy, v. 118, p. 1-12, 2016. https://doi.org/10.1016/j.energy.2016.10.138

MONTEIRO, C.; BESSA, R.; MIRANDA, V.; BOTTERUD, A.; WANG, J.; CONZELMANN, G. Wind power forecasting: State-of-the-art 2009. Argonne: Argonne National Laboratory, 2009. 216 p.http://dx.doi.org/10.2172/968212

MONTEZANO, B. E. M. Estratégias para identificação de sítios eólicos promissores usando sistema de informação geográfica e algoritmos evolutivos. 2012. Dissertação (Mestrado em Engenharia Civil) - Universidade Federal do Rio de Janeiro, Rio de Janeiro, 2012.

NETHERLANDS. Ministry Of Economic Affairs. Market study: wind energy in Brazil. Zeist: Larive International, 2014.

OPERADOR NACIONAL DO SISTEM ELÉTRICO - ONS. Sistema interligado nacional. Brasília, 2015.

PACHECO, C. S. G. R.; SANTOS, R. P. Parques eólicos e transformações espaciais: Uma análise dos impactos socioambientais na região de Sento Sé/BA. Revista Brasileira de Geografia Física, v. 5, p. 1243-1258, 2012.

PAZHERI, F. R.; OTHMAN, M. F.; MALIK, N. H. A review on global renewable electricity scenario. Renewable and Sustainable Energy Reviews, n. 31, p. 835-845, 2014. https://doi.org/10.1016/j.rser.2013.12.020

PINTO, L. I. C.; MARTINS, F. R.; PEREIRA, E. B.; FISCH, G. F.; LYRA, R. F. DA F. Confiabilidade nas estimativas do regime do vento fornecidas pelo BRAMS no estado de alagoas: influência do aninhamento e da resolução horizontal de grades. Revista Brasileira de Meteorologia, v.29, n.2, p. 242-258, 2014a. http://dx.doi.org/10.1590/S0102-77862014000200008

PINTO, M. F.; NASCIMENTO, J. L. J. DO; BRINGEL, P. C. F.; MEIRELES, A. J. DE A. Quando os conflitos socioambientais caracterizam um território? Gaia Scientia, p. 271 288,2014 b.

PINTO, L. I. C.; PEREIRA, E. B.; MARTINS, F. R.; LYRA, R. F. DA F. Avaliação comparativa de simulações numéricas de vento utilizando o modelo de mesoescala BRAMS. Revista Brasileira de Energia Solar, v.3, p. 138-147, 2012.

POTTMAIER, D.; MELO, C. R.; SARTOR, M. N.; KUESTER, S.; AMADIO, T. M.; FERNANDES, C. A. H. et al. The Brazilian energy matrix: From a materials science and engineering perspective. Renewable and Sustainable Energy Reviews, v. 19, p. 678691, 2013. https://doi.org/10.1016/j.rser.2012.11.063

PRODES. Monitoramento da Floresta Amazônica Brasileira por satélite. INPE, 2015. Disponível em: http://www.obt.inpe.br/prodes

RAMOS, D. N. S.; LYRA, R. F. DA F.; SILVA JUNIOR, R. S. Previsão do vento utilizando o modelo atmosférico WRF para o estado de Alagoas. Revista Brasileira de Meteorologia, v. 28, n. 2, p. 163-172, 2013.

RAMPINELLI, G. A.; ROSA JÚNIOR, C. G. Análise da geração eólica na matriz brasileira de energia elétrica. Revista Ciências Exatas e Naturais, v. 14, n. 2, p. 273-302, 2012. 
RICOSTI, J. F. C. Inserção da energia eólica no sistema hidrotérmico Brasileiro. 2011. Dissertação (Mestrado em Energia) - Universidade de São Paulo, São Paulo, 2011.

RODMAN, L. C.; MEENTEMEYER, R. K. A geographic analysis of wind turbine placement in Northern California. Energy Policy, v. 34, p. 2137-2149, 2006. https://doi.org/10.1016/j.enpol.2005.03.004

SALGUEIRO, T. B. Paisagem Geografia. Finisterra, v. 36, n. 72, p. 37-53, 2001.

SANTOS, M. J.; FERREIRA, P.; ARAÚJO, M.; PORTUGAL-PEREIRA, J.; LUCENA, A. F. P.; SCHAEFFER, R. Scenarios for the future Brazilian power sector based on a multicriteria assessment. Journal of Cleaner Production, 2017. http://dx.doi.org/10.1016/j.jclepro.2017.03.145

SCHMIDT, J.; CANCELLA, R.; PEREIRA JÚNIOR, A. O. An optimal mix of Schmidt PV, wind and hydro power for a low-carbon electricity supply in Brazil. Renewable Energy, v. 85, p. 137-147, 2016. https://doi.org/10.1016/j.renene.2015.06.010

SILVA, N. F.; ROSA, L. P.; ARAÚJO, M. R. The utilization of wind energy in the Brazilian electric sector's expansion. Renewable and Sustainable Energy Reviews, v.9, p. 289309, 2005. https://doi.org/10.1016/j.rser.2004.04.003

SILVA, S. T. Poluição visual e poluição sonora: aspectos jurídicos. Revista de Informação Legislativa, v. 40, n. 159, p. 161-179, 2003.

SIMAS, M.; PACCA, S. Energia eólica, geração de empregos e desenvolvimento sustentável. Estudos Avançados, v. 27, n. 77, p. 99-115, 2013. http://dx.doi.org/10.1590/S010340142013000100008

VAN KOOTEN, G. C. All you want to know about the economics of wind power. Working Paper 2015-07. REPA Resource Economics \& Policy Analysis Research Group. Victoria: Department of Economics, University of Victoria, 2015. 85 p.

VISSERING, J.; SINCLAIR, M.; MARGOLIS, A. A visual impact assessment process for wind energy projects. 2011. Disponível em: http://publicservice.vermont.gov/energy/ee_files/wind/psb_wind_siting_handbook.pdf

WOLSINK, M. Wind power and the NIMBY-myth: institutional capacity and the limited significance of public support. Renewable Energy, v. 21, p.49-64, 2000. https://doi.org/10.1016/S0960-1481(99)00130-5 